\title{
LIMITES E POSSIBILIDADES DA INTEGRAÇÃO CURRICULAR NO INSTITUTO FEDERAL CATARINENSE: REFLEXÕES A PARTIR DA FORMAÇAO CONTINUADA DE PROFESSORES
}

\author{
Filomena Lucia Gossler Rodrigues da Silva ${ }^{1}$, Andressa Graziele Brandt ${ }^{2}$, Tamiris Possamai ${ }^{3}$, \\ ${ }^{1}$ Doutora em Educação pela Universidade Federal de Santa Catarina - UFSC. Professora nos cursos de licenciatura e no \\ Programa de Pós-graduação em Educação do Instituto Federal de Educação, Ciência e Tecnologia Catarinense - IFC, \\ Campus Camboriú, SC; Coordenadora do Programa de Pós-graduação em Educação do Instituto Federal de Educação, \\ Ciência e Tecnologia Catarinense - Campus Camboriú, SC. ORCID iD: https://orcid.org/0000-0002-8275-7714. E-mail: \\ filomena.silva@ifc.edu.br. \\ ${ }^{2}$ Doutora em Educação pelo PPGE da Universidade Federal de Santa Catarina - UFSC. Pedagoga do Instituto Federal \\ Catarinense - IFC, Campus Camboriú, SC. ORCID iD: https://orcid.org/0000-0002-8176-1930. E-mail: \\ andressabrandt@hotmail.com. \\ ${ }^{3}$ Mestranda no Programa de Pós-Graduação em Educação do Instituto Federal Catarinense - IFC, Campus Camboriú, \\ SC. Técnica Administrativa em Educação no Instituto Federal Catarinense - IFC, Campus Rio do Sul. ORCID ID: \\ https://orcid.org/0000-0001-6107-1257. E-mail: tamiris.possamai@ifc.edu.br
}

\section{RESUMO}

Neste trabalho, sistematizamos algumas das reflexões realizadas a partir de uma formação continuada com professores(as) de Ensino Básico Técnico e Tecnológico do Instituto Federal Catarinense (IFC) - Campus Camboriú, acerca dos limites e das possibilidades da integração curricular nos cursos de Ensino Médio Integrado. O percurso metodológico, de caráter qualitativo, baseou-se na revisão de literatura, análise documental e pesquisa participante junto aos professores(as) do IFC. Entre os resultados, identificamos que os(as) professores(as) compreendem que a concepção de integração curricular exige tanto reestruturação dos projetos pedagógicos dos cursos e, consequentemente, dos currículos, quanto repensar as práticas pedagógicas de forma que estas contemplem a interdisciplinaridade que a realidade exige. Entre os limites e as possibilidades para a viabilização do currículo integrado, estão aspectos de ordem administrativa e pedagógica que revelam amplo conhecimento da instituição por parte dos docentes e, também, reconhecimento da existência de condições materiais concretas para a materialização da formação integral dos estudantes presente na concepção do Ensino Médio Integrado, entre elas a formação continuada.

Palavras-chave: Integração Curricular. Formação de Professores. Ensino Médio Integrado.

\section{LIMITS AND POSSIBILITIES OF CURRICULUM INTEGRATION IN THE INSTITUTO FEDERAL CATARINENSE: REFLECTIONS FROM THE CONTINUING EDUCATION OF TEACHERS}

\begin{abstract}
In this work, we systematize some of the reflections carried out based on continuing education with teachers of Basic Technical and Technological Education at the Instituto Federal Catarinense (IFC) - Campus Camboriú, Brazil, about the limits and possibilities of curricular integration in Integrated High School courses. The methodological approach, of qualitative character, was based on literature review, document analysis and participant research along with the teachers from the IFC. Among the results, we identified that teachers understand that the concept of curricular integration requires both restructuring the pedagogical projects of the courses and, consequently, the curricula, as well as rethinking the pedagogical practices so that they contemplate the interdisciplinarity that the reality requires. Among the limits and possibilities for the viability of the integrated curriculum, there are aspects of administrative and pedagogical order that reveal wide knowledge of the institution by the teachers and, also, recognition of the existence of concrete material conditions for the materialization of the integral education of the students present in the concept of Integrated High School, including continuing education.
\end{abstract}


Keywords: Curricular Integration. Teacher Education. Integrated High School.

\section{LÍMITES Y POSIBILIDADES DE LA INTEGRACIÓN CURRICULAR EN EL INSTITUTO FEDERAL CATARINENSE: REFLEXIONES A PARTIR DE LA FORMACIÓN CONTINUA DE PROFESORES}

\section{RESUMEN}

En este trabajo, están sistematizadas algunas de las reflexiones realizadas a partir de una formación continua con docentes de Educación Básica Técnica y Tecnológica del Instituto Federal Catarinense (IFC) Campus Camboriú, Brasil, acerca de los límites y de las posibilidades de la integración curricular en los cursos de la Enseñanza Secundaria Integrada. La trayectoria metodológica, de carácter cualitativo, se basó en la revisión de literatura, análisis de documentos e investigación participativa con profesores del IFC. Entre los resultados, identificamos que los docentes comprenden que la concepción de integración curricular exige tanto reestructuración de los proyectos pedagógicos de los cursos y, consecuentemente, de los currículos, así como repensar las prácticas pedagógicas de forma a que éstas contemplen la interdisciplinariedad que la realidad exige. Entre los límites y las posibilidades para la viabilización del currículo integrado están los aspectos de carácter administrativo y pedagógico que revelan amplio conocimiento de la institución por parte de los docentes $y$, también, el reconocimiento de la existencia de condiciones materiales concretas para la materialización de la formación integral de los estudiantes presentes en la concepción de la Enseñanza Secundaria Integrada, entre ellas la formación continua.

Palabras-clave: Integración Curricular. Formación de Profesores. Enseñanza Secundaria Integrada.

\section{INTRODUÇÃO}

As discussões acerca do currículo do Ensino Médio são recorrentes no contexto da Educação Brasileira, pois há, no cenário latinoamericano, um conjunto de influências de grupos econômicos e organismos multilaterais que colocam a educação a serviço do mercado (DOURADO, 2007; FREITAS, 2015; HYPOLITO, 2015). Vale mencionarmos que as mudanças que vêm ocorrendo no campo do currículo da última etapa da Educação Básica repercutem nas políticas de formação de professores. Esse movimento faz parte, portanto, da lógica perversa do capital comprometida com um projeto societário excludente e produtor de desigualdades.

Para Goodson (1995), o processo de fabricação do currículo não é lógico, mas um processo social, o qual convive, lado a lado, com fatores lógicos, epistemológicos, intelectuais, determinantes sociais menos nobres e menos formais, tais como interesses, rituais, conflitos simbólicos e culturais, necessidades de legitimação do controle, propósitos de dominação dirigidos por fatores ligados à classe, à raça, ao gênero.

No que diz respeito às alterações curriculares da última etapa da Educação Básica no Brasil, recentemente passamos por uma Reforma do Ensino Médio (Lei $\mathrm{N}^{\circ} 13.415$, de 16 de fevereiro de 2017), cuja concepção de formação que a circunscreve consiste em uma formação precária para as juventudes. Precária no sentido de que ela traz consigo a lógica perversa da formação básica frágil, baseada no desenvolvimento de competências, prevendo uma carga horária de apenas 1.800 horas da Base Nacional Comum Curricular - BNCC, e outras 1.200 horas para disciplinas que comporão um dos cinco percursos formativos: Linguagens e Suas Tecnologias; Matemática e Suas Tecnologias; Ciências a Natureza e Suas Tecnologias; Ciências Humanas e Sociais Aplicadas; e Formação Técnica e Profissional.

Entre outros prejuízos produzidos pela Reforma, está o fato de que o Ensino Médio, como última etapa da Educação Básica, retira do estudante o direito do acesso aos conhecimentos básicos de todas as ciências ao restringir os componentes curriculares de Português e de Matemática como únicos que deverão estar presentes nos três anos de duração da etapa mencionada. Há de dizermos que à sociedade é vendida a falsa ideia de escolha pelo jovem de um percurso formativo, que melhor atenda às suas expectativas e aos seus interesses de formação. Não se menciona, no entanto, que essa escolha será dos sistemas de ensino, de acordo com suas possibilidades. Em termos práticos, a implantação da Reforma do Ensino 
Médio vem sendo realizada sem que professores e tampouco os jovens tenham clareza da formação que o percurso formativo "escolhido" oferecerá. Não há clareza nem dos componentes curriculares, tampouco da concepção que tal formação representa.

$\mathrm{Na}$ acepção dos curriculistas e de pesquisadores da área da educação, a implementação da reforma é perversa e representa retrocesso nos processos educativos e formativos dos jovens e na perda da autonomia das escolas e de seus professores no sentido de construir uma educação comprometida com a formação integral dos jovens e a emancipação humana. Lamentavelmente, muitos professores, alheios a essa discussão, sequer têm percebido que esses e outros impactos nefastos dessa reforma alcançarão sua formação inicial e continuada, o trabalho docente, as práticas pedagógicas e a concepção de educação que caminha na contramão da autonomia e da emancipação dos sujeitos (SHIROMA; EVANGELISTA, 2011; FREITAS, 2015).

As alterações dos currículos da Educação Básica, decorrentes da aprovação da BNCC, em 2017 (Educação Infantil e Ensino Fundamental) e em 2018 (Ensino Médio), produzirão impactos, inclusive, sobre a formação dos professores, conforme destacam Bazzo e Scheibe (2019, p. 682):

Cada vez mais o professor deverá ter sua formação intrinsecamente ordenada pela BNCC, formulada no interior de uma política de reorientação curricular adotada por vários países, entre eles o Brasil, cujas alianças sociais, políticas e econômicas estão sendo construídas no interior da racionalidade neoliberal na educação, que atende prioritariamente aos interesses dos setores privados em sua lógica empresarial [...].

Tendo presente o exposto, compreendemos que, a formulação da BNCC da Educação Básica e a Base Nacional Comum da Formação de Professores e a indução para a sua implementação via reestruturação dos projetos pedagógicos dos cursos de licenciatura são instrumentos de aprofundamento da lógica neoliberal das políticas educacionais brasileiras e revelam o compromisso dos governantes com a conservação do projeto societário capitalista que produz e aprofunda desigualdades socioculturais e educacionais.

O mesmo ocorre com a reforma do ensino médio que altera não somente a carga horária da formação, ampliando a formação em itinerários formativos específicos e reduzindo a formação geral, negando aos jovens o acesso à solida formação básica que produz elementos importantes para a formação crítica dos jovens e sua emancipação no sentido de exercer sua cidadania plena. A esse respeito, entendemos que a concepção dos cursos de Ensino Médio Integrado na Rede Federal de Educação Profissional, Científica e Tecnológica, pela concepção de formação integral que possui, têm produzido experiências profícuas no que diz respeito não só à formação dos jovens, mas também dos professores que atuam nesses cursos, que consideramos ser inovadoras no ponto de vista pedagógico e epistemológico, garantindo a um só tempo o acesso ao itinerário formativo da educação profissional e uma sólida formação básica aos estudantes.

Assim, tendo como propósito compartilhar a experiência do Instituto Federal de Educação, Ciência e Tecnologia Catarinense (IFC), no que diz respeito a garantir uma formação integral dos estudantes da última etapa da Educação Básica, objetivamos, com este artigo, sistematizar algumas das reflexões realizadas a partir de uma formação continuada com 120 professores(as) de Ensino Básico Técnico e Tecnológico do IFC - Campus Camboriú acerca dos limites e das possibilidades da integração curricular nos cursos de Ensino Médio Integrado.

\section{DELINEAMENTO METODOLÓGICO}

De acordo com Barros e Lehfeld (1990, p. 14), a pesquisa "[...] é o procedimento sistemático e intensivo, que tem por objetivo descobrir e interpretar os fatos que estão inseridos em uma determinada realidade. A pesquisa é definida como uma forma de estudo de um objeto". Tendo presente essa definição de pesquisa, a escolha pela abordagem qualitativa deu-se pela especificidade do objeto deste trabalho, que, conforme já mencionado, consiste em sistematizar algumas das reflexões realizadas a partir de uma formação continuada com 120 professores(as) de Ensino Básico Técnico e 
contemplando, além da introdução e do delineamento metodológico, uma apresentação do percurso da construção dos currículos integrados do IFC e a análise dos registros das narrativas dos(as) professores(as) sobre sua implementação.

\section{PERCURSO DA CONSTRUÇÃO DOS CURRÍCULOS INTEGRADOS NO IFC}

Os primeiros passos do longo processo de (re)construção dos currículos integrados do IFC foram dados, a partir de e-book institucional que conta parte dessa trajetória, ainda no ano de 2012, quando foi constituído o Grupo de Trabalho "Ensino Médio Integrado", "[...] composto por profissionais da educação efetivos (docentes, técnicos em assuntos educacionais e pedagogos) pertencentes aos campi do Instituto Federal Catarinense" (IFC, 2017, p. 9). Seu principal objetivo era refletir acerca do Ensino Médio Integrado à Educação Profissional no IFC e sistematizar discussões desencadeadas em todos os campi no período de 2012 a 2017. Tais discussões, orientadas por documentos legais e por referenciais teóricos que sustentam uma concepção emancipadora de educação, representaram um passo importante para a construção de políticas internas e de percursos formativos comprometidos com uma formação integral a ser ofertada aos estudantes que chegam à instituição para cursar a última etapa da Educação Básica combinada com um curso técnico de nível médio.

Os estudos e as atividades do Grupo de Trabalho "Ensino Médio Integrado" (GTEMI) subsidiaram os encaminhamentos posteriores dados pela gestão do IFC. Desta movimentação inicial decorreram discussões sobre o Ensino Médio Integrado em todos os campi da instituição e, diante do cenário nacional de reformulação do Ensino Médio, inicia-se um amplo movimento de construção coletiva de diretrizes para a Educação Profissional Técnica Integrada ao Ensino Médio do IFC. Destaca-se, entre os encaminhamentos, a realização de dois seminários ampliados (2017-2018) e de quinze audiências públicas (2017) a fim de provocar, discutir e propor um documento-base que atendesse às especificidades dos cursos integrados do IFC.

As proposições registradas durante as audiências públicas, realizadas em 2017, voltaram-se para 7 eixos: Avaliação; Curricularização da Extensão; Curricularização da
Pesquisa; Currículo; Formação Integral; Organização dos Cursos; Outros. Durante esta fase de construção das Diretrizes institucionais, o arquivo com os registros das audiências denota a colaboração de docentes, técnicosadministrativos e discentes do IFC, assim como por mães e pais de discentes e representantes de órgãos externos. $O$ documento-base pretendido seguiu sendo discutido e aprimorado durante os anos de 2018 e 2019 até que, em março de 2019 após aprovação do Conselho Superior do IFC, é publicada a Resolução no 016/2019/CONSUPER/IFC que define as Diretrizes para a Educação Profissional Técnica Integrada ao Ensino Médio do IFC.

O amplo movimento que envolveu a construção coletiva de políticas e de direcionamentos institucionais, evidentemente, não ocorreu sem enfrentamentos, uma vez que, conforme observamos nas teorizações dos curriculistas, o currículo é sempre um campo de disputa (LOPES; MACEDO, 2011). As disputas por concepções e projetos educacionais estão presentes nos mais diversificados complexos sociais, e, como não poderia deixar de ser, é no contexto da prática, no cotidiano de cada campus, que o debate possui efervescência e também se materializa. Nesse sentido, o processo de iniciar tal construção, dialeticamente, também inicia a desconstrução de uma educação profissional marcada pelas determinações da sociedade do capital, comprometida com um modelo de formação de nível médio alinhado com a formação de mão de obra para o mercado de trabalho.

0 processo de socialização das discussões, dos eventos realizados, dos documentos construídos que nortearam os estudos e o cronograma de encontros está disponível no site oficial do IFC ${ }^{1}$. Ao analisarmos as informações disponíveis, observamos a existência de um esforço institucional em sistematizar o percurso da construção das Diretrizes para o Ensino Técnico Integrado no IFC. Faz parte dessa trajetória a criação, em 2018, da Comissão Institucional Permanente de Implantação e Acompanhamento das Diretrizes dos Cursos de Educação Profissional Técnica integrada ao Ensino Médio (CIPATEC), que, de caráter propositivo e consultivo, tem o objetivo de fomentar políticas que caminhem para a

\footnotetext{
1 Disponível em: https://ifc.edu.br/2017/09/13/caminhando-econstruindo-diretrizes-para-o-ensino-tecnico-integrado-do-ifc/. Acesso em: 10 jul. 2020
} 
consolidação dos cursos a partir das Diretrizes. Essa comissão é composta por membros da comunidade escolar (gestores, professores, técnico administrativos em educação) que possibilitam a elaboração e a implementação de projetos pedagógicos e, também, que currículos e práticas pedagógicas sejam construídas, implementadas e avaliadas em cada um dos 15 campi do IFC.

A reestruturação dos documentos - e, também, da instituição de novos percursos formativos, baseados na integração curricular que pretende subsidiar a formação integral dos estudantes e a consolidação de uma concepção emancipadora de educação - partiu da definição de um perfil do egresso de cada curso, construído após estudos realizados pelo coletivo de profissionais envolvidos. A definição dos componentes curriculares toma, portanto, como ponto de partida, o perfil do egresso de forma que os percursos integrados se comprometam com a formação integral proposta nas Diretrizes para a Educação Profissional Técnica Integrada ao Ensino Médio, que se materializam por meio da Resolução № 016/2019/CONSUPER/IFC (IFC, 2019). O documento demonstra um importante posicionamento de resistência e convergência

[...] aos interesses e às

necessidades da

população excluída,

portanto, dos grupos humanos hoje marginalizados, a exemplo dos estudantes oriundos da classe trabalhadora mais empobrecida. Diante desse contexto, novos e importantes desafios se estabelecem ao IFC no sentido de assegurar que seus currículos se mantenham

comprometidos com a concepção teóricometodológica da Educação Profissional Técnica, visando à formação omnilateral. (IFC, 2019, p. 2-3).

Ainda, a Resolução № 016/2019/CONSUPER/IFC, que se fundamenta observando a legislação vigente, menciona expressamente a concepção e os princípios norteadores presentes na Resolução CNE/CEB № 6 , de 20 de setembro de 2012, que define as
Diretrizes Curriculares Nacionais para a Educação Profissional Técnica de Nível Médio (BRASIL, 2012), construída também em um cenário de disputa. Consideramos importante mencionar que, durante o período em que o IFC constituía o GT do Ensino Médio Integrado e mobilizava um amplo movimento institucional de discussão, acerca da concepção de Ensino Médio comprometido com uma educação emancipadora e uma formação integral dos estudantes, o cenário nacional caminhava na direção oposta.

No âmbito nacional, foi instituída a Comissão Especial pelo Congresso Nacional para estudar uma reformulação do Ensino Médio, sob a justificativa de que "[...] o ensino médio oferecido atualmente não corresponde às expectativas dos jovens, especialmente no tocante à sua inserção na vida profissional, e vem apresentando resultados que não correspondem ao crescimento social e econômico do país" (SILVA; KRAWCZYK, 2016, p. 2). Isso resultou no Projeto de Lei № 6.840/2013 (BRASIL, 2013). Sua ementa apontava para a alteração na Lei № 9.394, de 20 de dezembro de 1996 (Lei de Diretrizes e Bases da Educação Nacional - LDB), instituindo jornada em período integral e dispondo sobre organização de currículos do Ensino Médio por áreas do conhecimento.

O PL № 6.840/2013 teve sua última movimentação em 2016, ano em que, após articulações e manobras de forças contrárias ao Partido da Presidência da República, houve o processo de impeachment da Presidenta Dilma Rousseff, que mudou novamente a conjuntura política do país. O vice-presidente Michel Temer, ao assumir o cargo, emitiu uma Medida Provisória (MP) com o fito de aligeirar o processo de alteração da LDB de 1996 e do FUNDEB (Lei № 11.494, de 20 de junho de 2007) e de reformulação do Ensino Médio brasileiro. Por meio da MP № 746/2016, propôs alterações que, em uma tramitação de urgência (conforme característica de uma MP), negligenciou o debate com os principais envolvidos e impactados, que culminou na Lei № 13.415/2017, aprovada em fevereiro de 2017: A Reforma do Ensino Médio. Para Scheibe e Silva (2017, p. 21),

[...] a atual reforma está sustentada na defesa da necessidade de adequação do ensino médio a requisitos postos pelo mercado de trabalho e/ou por necessidades definidas 
pelo setor empresarial. Tal defesa aproxima a última etapa da educação básica a uma visão mercantil da escola pública e adota critérios pragmáticos para definir os rumos da mudança [...].

Ao passo que essa reforma vem sendo implementada, vários pontos preocupam e apresentam-se como verdadeiras ameaças à oferta de Educação Profissional Integrada ao Ensino Médio pelos Institutos Federais, sobretudo ao IFC que vem fortalecendo sua defesa em relação à oferta de percursos formativos e educativos alicerçados em uma concepção de educação pública, gratuita, laica, inclusiva, democrática e de qualidade social referenciada.

\section{COMPREENSÃO DOS(AS) PROFESSORES(AS) DO IFC ACERCA DO CURRÍCULO INTEGRADO: REFLEXÕES A PARTIR DA FORMAÇÃO CONTINUADA}

De acordo com Lopes e Macedo (2011, p. 123), “[...] ao longo da história do currículo, podem ser situadas inúmeras propostas de currículo integrado, sob denominações distintas: currículo global, metodologia de projetos, currículo interdisciplinar, currículo transversal". Contudo, cada uma dessas propostas, ao organizar seu currículo, há, segundo as autoras, diferentes formas de interpretar a integração, não se restringindo, portanto, às perspectivas críticas de educação.

Construir uma proposta de currículo integrado a partir das perspectivas críticas da educação, considerando a realidade objetiva de cada curso de Ensino Médio Integrado à Educação Profissional no IFC tem sido um desafio para gestores, coordenação pedagógica e professores nos últimos anos. Observamos a existência de um amplo movimento de construção de Diretrizes específicas para tais cursos, fundamentadas na compreensão teórica e prática da concepção de integração curricular a partir de ações que se iniciaram no ano de 2012.

A experiência em curso, portanto, envolve a ampla participação dos docentes nos últimos oito anos, articulada à construção de Diretrizes para a Educação Profissional Técnica de Nível Médio e ao desenvolvimento de uma política de formação continuada. Desse processo, resultou a reestruturação e a implementação de projetos pedagógicos e currículos dos cursos de Ensino Médio Integrado, subsidiados pela concepção de educação profissional técnica de nível médio que, além de formar profissionais tecnicamente competentes, tenham como centralidade a formação de cidadãos comprometidos com uma sociedade mais justa.

O desafio de construir um currículo alicerçado na produção de sentido e significado para os estudantes, tanto no que diz respeito a sua formação cidadã quanto para a construção dos saberes necessários para o exercício de atividades profissionais que a formação profissional de nível médio oportuniza, vem sendo enfrentado diariamente, seja por meio da construção de políticas quanto de práticas. No tocante às políticas, observamos a aprovação de legislações e o desenvolvimento de um amplo movimento de formação continuada articulado à concepção de formação integral (profissional e cidadã, tendo presente todas as dimensões da vida humana). Em relação às práticas, observamos um amplo processo de diálogo construído durante as formações continuadas realizadas, que, nesse momento, tem como propósito materializar os projetos pedagógicos e os currículos dos cursos mencionados.

Tendo presente o exposto, apresentaremos e discutiremos dados coletados durante 0 desenvolvimento de uma das formações continuadas realizadas sobre o currículo integrado com os professores e demais profissionais de educação do IFC - Campus Camboriú, coordenadas pelas autoras do artigo. Selecionamos registros que possam ilustrar a compreensão desses professores acerca do currículo integrado, os limites e as potencialidades de implementação nesse campus.

No que diz respeito à compreensão de currículo integrado, as falas dos professores revelam: a) que ele envolve a interdisciplinaridade, uma vez que os conteúdos se complementam e dialogam entre si e com a prática profissional; b) que implica pensar a formação, sem dissociar atividades de ensino, pesquisa e extensão; c) que os componentes curriculares e suas ementas precisam estar voltados ao perfil do egresso; d) que implica associar/articular/aproximar as disciplinas/professores/estudantes; exige, assim, dialogicidade. 
As respostas dos(as) professores(as) sinalizam que a elaboração dos currículos, principalmente sua implementação, depende de uma construção coletiva que articula teoria e prática. Essa articulação exige diálogo entre os envolvidos no processo educativo para que os conhecimentos possam produzir sentido e significado para os estudantes. Práticas pedagógicas alicerçadas nessa compreensão, em nossa análise, são potencialmente capazes de consolidar processos formativos comprometidos com a formação integral dos estudantes na Rede Federal de Educação Profissional e Tecnológica. Essa formação envolve uma dupla finalidade: uma formação técnica que ofereça condições para a inserção no mundo do trabalho e uma formação que ofereça instrumentos para $o$ exercício pleno da cidadania por meio do desenvolvimento de todas as dimensões do ser humano como a dimensão intelectual (científica e tecnológica), ética, estética, política, sociocultural, entre outras. Para dar conta dessa dupla finalidade,

[...] os conhecimentos das ciências denominadas duras e os das ciências sociais e humanas serão contemplados de forma equânime, em nível de importância e de conteúdo, visando a uma formação integral do cidadão autônomo e emancipado. A formação integral implica competência técnica e compromisso ético, que se traduzam em atuação voltada para a edificação de uma sociedade justa e igualitária. (MOURA, 2010, p. 5-6).

Podemos observar nessa afirmação de Moura (2010) e tendo presente os registros da formação anteriormente expostos, o currículo integrado exige que os conhecimentos acessados e construídos visem a dinâmica da integralidade. Dito de outro modo, os conhecimentos necessitam ser vistos a partir da perspectiva da interdisciplinaridade e da contextualização dos saberes historicamente acumulados articulados às experiências que os estudantes possuem e à(s) realidade(s) socioculturais, políticas, econômicas que estamos inseridos. Nessa perspectiva, é a realidade, a dinâmica viva do currículo que irá exigir a interdisciplinaridade. Desse modo:

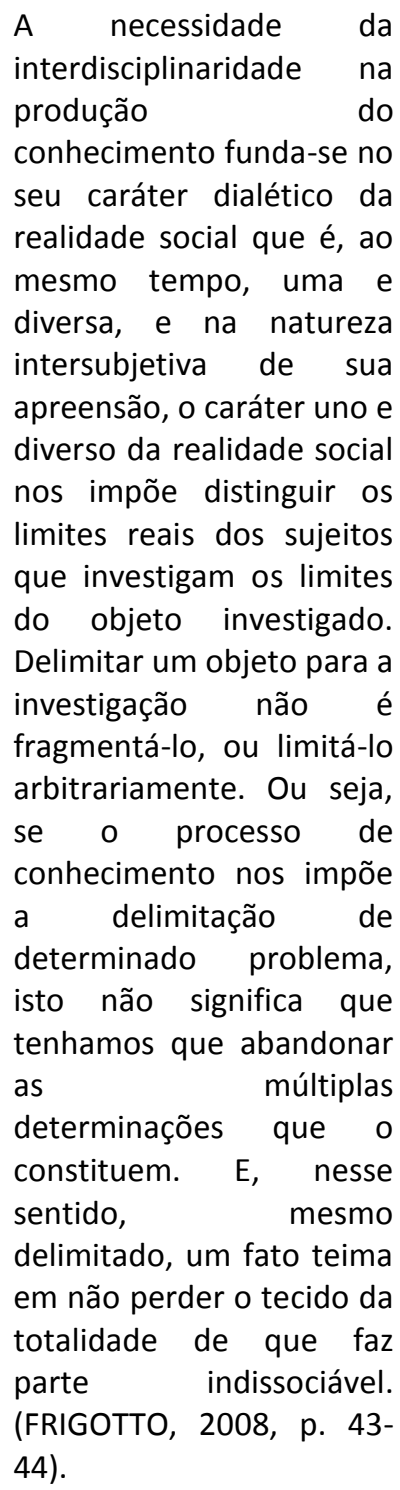

Assim, a partir de Frigotto (2008) e em diálogo com Silva (2016, p. 10), entendemos que "[...] se as ações humanas se materializam a partir de práticas concretas, as práticas cotidianas na sala de aula apresentam-se então como um espaço/tempo privilegiado para a mobilização de saberes individuais e coletivos saberes que agem, que pensam, que teorizam, que constroem e reconstroem". Aí está o desafio posto aos(às) professores(as): tornar os processos educativos espaços privilegiados para a formação integral dos jovens estudantes.

A partir da identificação de que os(as) professores(as) participantes da formação possuem a compreensão de currículo integrado, buscamos refletir sobre os limites, as dificuldades e as necessidades observadas pelo coletivo para a construção e a implementação de currículos integrados no IFC-Campus Camboriú. 
Observamos, no diálogo estabelecido, que: a) são necessários encontros regulares entre os(as) professores(as) de modo que eles(as) conheçam os componentes curriculares ofertados em profundidade e possam dar materialidade à interdisciplinaridade; b) que os currículos/conteúdos estejam articulados com a missão e visão do IFC, assim como o Plano de Desenvolvimento Institucional e o Projeto Político Pedagógico Institucional; c) realizar trocas de experiências entre os(as) professores(as) do mesmo curso e de outros cursos; d) superar a dicotomia e a hierarquia entre disciplinas técnicas e básicas e as áreas do conhecimento; e) avançar na superação das questões burocráticas que dificultam alocação de carga horária para mais de um professor no mesmo horário e organização de horários que permitam o diálogo entre os pares.

Os aspectos mencionados, pelos(as) professores(as), que dificultam a materialização do currículo integrado são de duas ordens: uma administrativa e outra pedagógica. Administrativamente os professores requerem espaços e tempos coletivos para viabilizar o diálogo entre os pares e o cômputo de horas de aula envolvendo mais de um professor; assim, há a necessidade de espaços de formação continuada em serviço e de planejamento colaborativo. A esse respeito, recorremos a Hobold (2018), que, em suas análises e reflexões sobre 0 desenvolvimento profissional dos professores, menciona a necessidade de pesquisar e de valorizar os espaços formativos dos docentes, de forma a destacar a intencionalidade de trabalhar as questões de formação continuada nos processos ofertados internamente nas instituições de ensino.

No que diz respeito aos aspectos pedagógicos das demandas levantadas, ressaltamos que eles convergem com o sinalizado por Silva et al. (2016), que afirma que pensar um currículo integrado envolve tomar a interdisciplinaridade como um modo de fazer, como uma artesania coletiva, voltada à potencialização da formação geral, técnica, intelectual e cidadã dos educandos, visando que estes se reconheçam como sujeitos da história; e, também, pensar a formação integral dos sujeitos do processo educativo (estudante e professor).

Há de mencionarmos, ainda, que os limites e as necessidades levantados pelos(as) professores(as) possuem relação com a perspectiva da politecnia defendida por Saviani
(2003), que exigem pensar e realizar uma formação humanizada a partir do domínio dos fundamentos científicos e das diferentes técnicas que caracterizam 0 processo de trabalho moderno e conhecer as diferentes modalidades de trabalho, pois é preciso superar a "[...] dicotomia entre trabalho manual e trabalho intelectual, entre instrução profissional e instrução geral" (SAVIANI, 2003, p. 13). Ao contrário do que muitos pensam, a politecnia não é sinônimo de "ensino de muitas técnicas" ou de polivalência, mas significa "[...] uma educação que possibilita a compreensão dos princípios científico-tecnológicos e históricos da produção moderna, de modo a orientar os estudantes à realização de múltiplas escolhas" (RAMOS, 2008, p. 3).

O que nos parece evidente a partir do exposto é que o grande desafio que se coloca aos professores é a construção e a implementação de um currículo integrado que articule as necessidades de formação para o mundo do trabalho, tendo a pesquisa, a cultura, a tecnologia e o trabalho como pilares e em consonância com a heterogeneidade de sujeitos que ingressam nos Institutos Federais com as necessidades da formação cidadã. Articular tais necessidades implica reconhecer os sujeitos concretos, considerando suas trajetórias e os contextos em que vivem.

Considerando o exposto, reportamo-nos a Silva et al. (2018), que afirmam que o professor que atua na Educação Profissional fundamenta sua prática pedagógica transpondo didaticamente aquilo que aprendeu em sua formação inicial e aprendendo a ser professor por meio da sua experiência profissional. Daí a importância da construção de políticas de formação continuada em serviço que dialogam com as especificidades da docência no campo de atuação profissional do professor tendo em vista a construção de uma identidade convergente com os propósitos institucionais que, neste caso, corroboram para uma atuação comprometida com a formação integral dos estudantes.

Conforme Frigotto, Ciavatta e Ramos (2005), ao refletirem sobre a última etapa da Educação Básica, argumentam que são muitas as dualidades presentes no Ensino Médio e que se constituem em desafios a serem enfrentados, entre os quais mencionam: o desafio de uma formação técnica de nível médio especializados ou politécnicos; a formação de mão de obra para o mercado de trabalho ou de cidadãos para o 
mundo de trabalho; e, principalmente, o desafio de construir e desenvolver na práxis um currículo integrado que contemple de forma a formação geral, humanística e técnica.

Esses questionamentos relacionados ao processo de formação dos estudantes no Ensino Médio técnico são pertinentes e trazem à reflexão uma concepção de educação que privilegie a construção de uma escola única, integral e integrada ao Ensino Médio. Tal concepção, que integra a formação geral e técnica no Ensino Médio, “[...] é condição necessária para a travessia em direção ao ensino médio politécnico e à superação da dualidade educacional brasileira pela superação da dualidade de classes" (FRIGOTTO; CIAVATTA; RAMOS, 2005, p. 45).

Realizar uma educação comprometida com essa concepção requer $\operatorname{dos}(a s)$ professores(as) o desenvolvimento de culturas e práticas que a sustentem. As reflexões realizadas durante a formação continuada objetivaram, além de buscar compreender qual a concepção de currículo integrado e quais os limites, os desafios e as necessidades para sua realização, levantar quais são as possibilidades e as facilidades para a construção de currículos integrados.

Nesse sentido, segundo os(as) professores(as) que participaram da formação continuada, são facilidades e possibilidades do IFC - Campus Camboriú: a) a predisposição dos(as) professores(as) em debater o currículo integrado; b) a possibilidade de criar coletivos de professores(as) dispostos(as) a desenvolver atividades integrando diferentes disciplinas; c) a viabilidade de construir tempos e espaços de planejamento coletivo na carga horária semanal dos(as) professores(as); d) a reestruturação dos projetos pedagógicos e currículos do cursos de Ensino Médio Integrado; e) a existência de estrutura física que ofereça laboratórios e vários outros espaços; f) a constituição do corpo docente com qualificação em nível de pósgraduação e com dedicação exclusiva; g) a diversidade/coexistência de áreas de conhecimento; h) a missão institucional e da própria Rede Federal de Educação Profissional e Tecnológica que se compromete com a formação cidadã e técnica de excelência; i) a possibilidade de propor e de executar projetos de ensino, de pesquisa e de extensão; j) a realização de eventos que socializem as experiências de formação da instituição; k) a presença de professores e de estudantes em tempo integral na instituição; I) a existência de um calendário de formação continuada para o ano letivo (um período mensal); $m$ ) o acesso às experiências que ocorrem em outros Institutos Federais e do próprio Campus.

Conforme podemos observar nessa sistematização, existem condições concretas para a viabilização dos currículos integrados que possam produzir sentido e significado para a formação integral dos jovens estudantes do Ensino Médio. Os aspectos mencionados pelos(as) professores(as) reforçam a relevância da construção e da implementação de políticas de formação continuada de professores(as) que atuam no âmbito da Educação Profissional, Científica e Tecnológica, que superem medidas emergenciais, descontínuas e não obrigatórias (SILVA et al., 2018).

Em nossa acepção, o desafio de ensinar e de aprender nessa concepção de formação deve ser enfrentado diariamente de forma que a memória e a identidade dos cursos, da instituição e da própria Rede Federal de Educação Profissional, Científica e Tecnológica possa ecoar país afora. Assim, de acordo com Ciavatta (2005), a memória e a identidade escolar devem ser construídas de forma dinâmica e permanente, tendo suas raízes na cultura, no tempo e no lugar de onde os sujeitos sociais se inserem.

\section{CONSIDERAÇÕES FINAIS}

Entre os resultados obtidos na análise dos registros da formação continuada realizada junto aos(às) professores(as) do IFC, identificamos que estes(as) compreendem que a integração curricular exige tanto a reorganização curricular por meio da reestruturação dos projetos pedagógicos dos cursos como repensar as práticas pedagógicas, de modo a contemplar a perspectiva da interdisciplinaridade. Nesse sentido, a interdisciplinaridade não só envolve a articulação de saberes de diferentes áreas do conhecimento, como também abrange temas, conceitos, pesquisas e situações cotidianas como mecanismos que favorecem a compreensão de um determinado fenômeno ou aspecto da realidade.

A partir do estudo realizado entendemos ainda que a integração curricular realizada e a concepção presente nos cursos de Ensino Médio Integrado são aspectos importantes para a reconfiguração da identidade institucional IFC Campus Camboriú, alcançando os demais níveis 
de formação oferecidos pela instituição (cursos de qualificação profissional, graduação bacharelados, engenharias, licenciaturas - e pósgraduação lato e stricto sensu). Dizemos isso considerando que os(as) professores(as) da instituição atuam em diferentes níveis e etapas da educação, dando materialidade à nova institucionalidade da Rede Federal de Educação Profissional, Científica e Tecnológica, que consiste na verticalização da formação dos brasileiros em uma única rede de ensino.

Outro aspecto importante a ser mencionado diz respeito à compreensão dos profissionais do Campus, em relação ao processo de construção de um currículo integrado. Os depoimentos dos professores e a análise do percurso realizado para a construção de um currículo nesta perspectiva não se constrói em gabinetes, tampouco pode sofrer influência de representantes de organismos multilaterais, de modo a atender aos interesses do empresariado. O currículo integrado nasce de uma construção coletiva, fundamentada nos princípios da politecnia, de maneira a articular o domínio dos fundamentos da técnica e da ciência requeridos pelo mundo do trabalho com a formação humana integral, ética, estética, política, sociocultural, histórica, que possibilita a emancipação dos jovens estudantes do Ensino Médio.

Tal compreensão nos remete a conceber o currículo como elemento importante no processo de transformação da realidade concreta dos sujeitos envolvidos no processo educativo, quer sejam os estudantes, quer sejam os professores. Assim, conforme observamos nas análises realizadas, o professor, ao apropriar-se, por meio da formação continuada, da compreensão de que o currículo escolar não se limita a conteúdos curriculares definidos em uma Base Nacional Comum Curricular da formação dos jovens brasileiros, passa a compreendê-lo como um dos instrumentos de transformação social. Além disso, o movimento realizado para a construção de um currículo para os cursos de ensino médio integrado, que envolve a formação continuada e um intenso debate sobre a concepção de educação que alicerça os processos formativos e educativos, constituem-se em mecanismo de resistência por meio do desenvolvimento de culturas, de políticas e de práticas desenvolvidas em muitas instituições da Rede Federal de Educação profissional, científica e tecnológica país afora.
Em suma, compreendemos que as políticas de formação continuada em serviço são essenciais para que, conforme sinalizam Silva et al. (2018), que a atuação dos(as) professores(as) possa vir a se comprometer com uma perspectiva/concepção de Educação Profissional, Científica e Tecnológica emancipatória e integral para e com os sujeitos que frequentam essa modalidade de ensino, alinhada tanto aos princípios da Rede Federal que se propõe a oferecer uma educação de qualidade social referenciada, quanto ao alcance das metas do Plano Nacional de Educação.

Tendo presente o exposto, corroboramos com Santomé (1998) na defesa de que poucas vezes ao longo da história foi tão urgente a aposta em uma educação verdadeiramente comprometida com valores da democracia e da solidariedade se quisermos enfrentar as políticas neoliberais alinhadas aos interesses da sociedade capitalista que colocam o consumo e o lucro acima da vida, da solidariedade e da dignidade humana.

\section{REFERÊNCIAS}

BARROS, A. J. P.; LEHFELD, A. S. Projeto de pesquisa: propostas metodológicas. 8. ed. Petrópolis: Vozes, 1990.

BAZZO, V.; SCHEIBE, L. De volta para o futuro... retrocessos na atual política de formação docente. Revista Retratos da Escola, Brasília, v. 13, n. 27, p. 669-684, set./dez. 2019. Disponível em:

http://retratosdaescola.emnuvens.com.br/rde/ar ticle/view/1038. Acesso em: 10 jun. 2020.

DOI: $10.22420 /$ rde.v13i27.1038

BRASIL. Presidência da República. Casa Civil,.Subchefia para Assuntos Jurídicos. Lei № 9.394, de 20 de dezembro de 1996. Estabelece as diretrizes e bases da educação nacional. Brasília:, 1996. Disponível em: http://www.planalto.gov.br/ccivil 03/leis/19394. htm. Acesso em: 10 jun. 2020.

BRASIL. Presidência da República. Casa Civil. Subchefia para Assuntos Jurídicos. Lei $\mathbf{N}^{\circ}$ 11.494, de 20 de junho de 2007. Regulamenta o Fundo de Manutenção e Desenvolvimento da Educação Básica e de Valorização dos Profissionais da Educação - FUNDEB, de que trata o art. 60 do Ato das Disposições Constitucionais Transitórias; altera a Lei $\mathrm{n}^{\circ} \mathbf{1 0 . 1 9 5}$, de 14 de 
fevereiro de 2001; revoga dispositivos das Leis $\mathrm{n}^{\text {os }} 9.424$, de 24 de dezembro de 1996, 10.880, de 9 de junho de 2004, e 10.845, de 5 de março de 2004; e dá outras providências. Brasília: 2007. Disponível em: http://www.planalto.gov.br/ccivil 03/ ato20072010/2007/lei//11494.htm. Acesso em: 10 jun. 2020.

BRASIL. Lei № 13.415 , de 16 de fevereiro de 2017. Altera as Leis $\mathrm{N}^{\text {os }} 9.394$, de 20 de dezembro de 1996, que estabelece as diretrizes e bases da educação nacional, e 11.494, de 20 de junho 2007, que regulamenta o Fundo de Manutenção e Desenvolvimento da Educação Básica e de Valorização dos Profissionais da Educação, a Consolidação das Leis do Trabalho - CLT, aprovada pelo Decreto-Lei no 5.452 , de 10 de maio de 1943, e o Decreto-Lei no 236, de 28 de fevereiro de 1967; revoga a Lei no 11.161 , de 5 de agosto de 2005; e institui a Política de Fomento à Implementação de Escolas de Ensino Médio em Tempo Integral. Diário Oficial da União: seção 1, Brasília, DF, n. 35, p. 1-3, 17 fev. 2017.

BRASIL. Congresso Nacional. Projeto de Lei № 6.840/2013. Altera a Lei no 9.394, de 20 de dezembro de 1996, que estabelece as diretrizes e bases da educação nacional, para instituir a jornada em tempo integral no ensino médio, dispor sobre a organização dos currículos do ensino médio em áreas do conhecimento e dá outras providências. Brasília, 2013. Disponível em:

https://www.camara.leg.br/proposicoesWeb/fich adetramitacao?idProposicao $=602570$. Acesso em: 10 jun. 2020.

BRASIL. Resolução № 6, de 20 de setembro de 2012. Define Diretrizes Curriculares Nacionais para a Educação Profissional Técnica de Nível Médio. Diário Oficial da União: seção 1, Brasília, DF, ano 149, n. 184, p. 22, 21 set. 2012.

CIAVATTA, M. A formação integrada: a escola e o trabalho como lugares de memória e de identidade. Revista Trabalho Necessário, Niterói, v. 3, n. 3, 2005. Disponível em: https://periodicos.uff.br/trabalhonecessario/artic le/view/6122. Acesso em: 10 jun. 2020. DOI: $10.22409 /$ tn.3i3.p6122
CUNHA, M. I. Conta-me agora! as narrativas como alternativas pedagógicas na pesquisa e no ensino. Revista da Faculdade de Educação, São Paulo, v. 23, n. 1-2, jan./dez. 1997. Disponível em:

https://www.scielo.br/scielo.php?script=sci artte xt\&pid=S0102-

25551997000100010\&lng=pt\&t|ng=pt. Acesso em: 10 ju. 2020. DOI: 10.1590/S0102$\underline{25551997000100010}$

DOURADO, L. F. Políticas e gestão da educação básica no Brasil: limites e perspectivas. Educ. Soc., Campinas. v. 28, n. 100, p. 921-946, 2007. Disponível em: https://www.scielo.br/pdf/es/v28n100/a142810 0.pdf. Acesso em: 11 out. 2020. DOI: 10.1590/S0101-73302007000300014

FREITAS, L. C. Avaliação educacional. Política educacional e base nacional. 2015.

Disponível em: https://avaliacaoeducacional.com/2015/09/18/p olitica-educacional-ebase-nacional-ii-2/. Acesso em: 3 set. 2020.

FRIGOTTO, G. A interdisciplinaridade como necessidade e como problema nas ciências sociais. Revista Ideação, Foz do Iguaçu, v. 10, n. 1, p. 41-62, 2008.

FRIGOTTO, G.; CIAVATTA, M.; RAMOS, M. N. (orgs.). Ensino Médio Integrado: concepção e contradições. São Paulo: Editora Cortez, 2005.

HYPOLITO, Á. L. M. Trabalho docente e o novo Plano Nacional de Educação: valorização, formação e condições de trabalho. Cad. Cedes, Campinas, v. 35, n. 97, p. 517-534, set./dez., $2015 . \quad$ Disponível em: https://www.scielo.br/pdf/ccedes/v35n97/16787110-ccedes-35-97-00517.pdf. Acesso em: 23 set. 2020. DOI: $10.1590 / C C 0101-32622015150376$

GOODSON, I. F. Currículo: Teoria e história. Tradução Attílio Brunetta. Revisão da tradução Hamilton Francischetti. 7. ed. Petrópolis: Vozes, 1995.

HOBOLD, M. de S. Desenvolvimento profissional dos professores: aspectos conceituais e práticos. Práxis Educativa, Ponta Grossa, v. 13, n. 2, p. 425-442, mai./ago. 2018. Disponível em: https://revistas2.uepg.br/index.php/praxiseducat 
iva/article/view/10336. Acesso em: 10 jun. 2020. DOI: 10.5212/PraxEduc.v.13i2.0010.

IFC. Instituto Federal Catarinense. Ensino Médio Integrado no IFC: estudos e reflexões. Blumenau: Editora IFC, 2017. Disponível em: http://ifc.edu.br/wp-

content/uploads/2017/09/Ensino-M\%C3\%A9dioIntegrado-no-IFC-1.pdf. Acesso em: 25 jun. 2020.

IFC. Instituto Federal Catarinense. Resolução № 016, de 1 de abril de 2019. Dispõe sobre as Diretrizes para a Educação Profissional Técnica Integrada ao Ensino Médio do Instituto Federal Catarinense. Blumenau: Conselho Superior do Instituto Federal Catarinense, 2019. Disponível em: $\quad$ http://consuper.ifc.edu.br/wpcontent/uploads/sites/14/2019/01/Resolu\%C3\% A7\%C3\%A30-16.2019-Diretrizes.pdf. Acesso em: 3 jul. 2020.

LOPES, A. C.; MACEDO, E. Teorias do currículo. São Paulo: Cortez, 2011.

MINAYO, M. C. de S. (org.). Pesquisa Social: teoria, método e criatividade. 26. ed. Petrópolis: Vozes, 2007.

MOURA, D. Algumas possibilidades de organização do ensino médio a partir de uma base unitária: trabalho, ciência, tecnologia e cultura. In: SEMINÁRIO NACIONAL: CURRÍCULO EM MOVIMENTO - PERSPECTIVAS ATUAIS, 1., 2020, Belo Horizonte. Anais eletrônicos [...]. Belo Horizonte: MEC, 2010. Disponível em: http://portal.mec.gov.br/docman/dezembro2010-pdf/7177-4-2-algumas-possibilidadesorganizacao-ensinomedio-dante-henrique/file. Acesso em: 18 jul. 2020.

RAMOS, M. Concepção do ensino médio integrado. 2008. Disponível em: http://forumeja.org.br/go/sites/forumeja.org.br. go/files/concepcao do ensino medio integrado5.pdf. Acesso em: 27 jul. 2020.

SANTOMÉ, J. T. Globalização e Interdisciplinaridade: o currículo integrado. Porto Alegre: Artes Médicas, 1998.

SAVIANI, D. O choque teórico da politecnia. Trabalho, Educação e Saúde, Rio de Janeiro, v. 1, n. 1, p. 131-152, mar. 2003. Disponível em: https://www.scielo.br/scielo.php?script=sci artte
xt\&pid=S1981-

$\underline{77462003000100010 \& \operatorname{lng}=p t \& t \operatorname{lng}=p t .} \quad$ Acesso em: 10 jun. 2020. DOI: 10.1590/S1981$\underline{77462003000100010}$

SHIROMA, E. EVANGELISTA, O. Avaliação e responsabilização pelos resultados: atualizações nas formas de gestão de professores. Perspectiva, Florianópolis, v. 29, n. 1, p. 127-160, 2011. Disponível em: . Acesso em 10 set. 2020. https://periodicos.ufsc.br/index.php/perspectiva Larticle/view/2175-795X.2011v29n1p127. DOI: $\underline{10.5007 / 2175-795 X .2011 v 29 n 1 p 127}$

SILVA, F. L. G. R. et al. A constituição dos saberes necessários ao exercício da docência na educação profissional, científica e tecnológica: um balanço das produções acadêmicas (2011 - 2016). Revista de Estudos e Pesquisas sobre Ensino Tecnológico, Manaus, v. 4, n. 9, p. 38-55, 2018. Disponível em: https://sistemascmc.ifam.edu.br/educitec/index. php/educitec/article/view/321. Acesso em: 10 jun. 2020.

SILVA, M. R.; KRAWCZYK, N. Quem é e o que propõe o Projeto de Lei da reforma do Ensino Médio: entrevistando $\mathrm{o}$ Projeto de Lei 6.840/2013. In: AZEVEDO, J. C. de; REIS, J. T. (orgs.). Ensino médio: políticas e práticas. Porto Alegre: Editora Universitária Metodista IPA, 2016. p. 47-64.

SILVA, A. L. et al. O currículo integrado no cotidiano da sala de aula. Florianópolis: IFSC, 2016. 